\title{
Multidimensional Family Therapy Reduces Self- Reported Criminality Among Adolescents With a Cannabis Use Disorder
}

International Journal of Offender Therapy and Comparative Criminology $1-16$

(C) The Author(s) 2017

Reprints and permissions: sagepub.com/journalsPermissions.nav DOI: $10.1177 / 0306624 \times 16687536$ journals.sagepub.com/home/ijo

๑SAGE

\author{
Thimo M. van der Pol',2, Craig E. Henderson ${ }^{3}$, \\ Vincent Hendriks'1,4, Michael P. Schaub5 \\ and Henk Rigter'
}

\begin{abstract}
Multidimensional family therapy (MDFT) is an established treatment program for youth displaying multiproblem behavior. We examined whether MDFT decreased criminal offending among cannabis abusing adolescents, as compared with individual psychotherapy (IP). In a Western European randomized controlled trial comparing MDFT with IP, a sample of 169 adolescents with a cannabis disorder completed self-reports on criminal offending. Half indicated they had committed one or more criminal offenses in the 90 days before the baseline assessment. Follow-up assessments were at 6 and 12 months after randomization. The proportion of adolescents reporting nondelinquency increased during the study period, most so in the MDFT condition. In addition, MDFT lowered the number of violent offenses more than IP. This difference was not seen for property crimes. In cannabis abusing adolescents, MDFT is an effective treatment to prevent and reduce criminal offending. MDFT outperforms IP for violent crimes.
\end{abstract}

\section{Keywords}

criminality, multidimensional family therapy, cannabis use disorder, multisite randomized controlled trial

'Curium, Leiden University Medical Center, The Netherlands

${ }^{2} \mathrm{VU}$ University Medical Center, Amsterdam, The Netherlands

${ }^{3}$ Sam Houston State University, Huntsville, TX, USA

${ }^{4}$ Parnassia Addiction Research Centre, The Hague, The Netherlands

${ }^{5}$ University of Zurich, Switzerland

\section{Corresponding Author:}

Thimo M. van der Pol, Department of Child and Adolescent Psychiatry, Curium, Leiden University Medical Center, P.O. Box 37, 2300 AA, Leiden The Netherlands.

Email: thimovanderpol@gmail.com 


\section{Background}

In adolescents, a behavioral problem — such as substance abuse, criminal offending, truancy, or symptoms of (other) mental health disorder-often is part of a broader multiproblem behavior constellation (Griffith-Lendering, Huijbregts, Mooijaart, Vollebergh, \& Swaab, 2011; Phan et al., 2011; Skeer, McCormick, Normand, Buka, \& Gilman, 2009). Common is the combination of substance use disorder and criminal behavior (delinquency; Copeland \& Swift, 2009; Fallu, Brière, \& Janosz, 2014; Hser et al., 2001; Hüsler, Plancherel, \& Werlen, 2005). Substance use disorders have been identified as a risk factor for criminal offending. Conversely, criminal offending is a risk factor for the development of substance use disorders (Moffitt, Caspi, Harrington, \& Milne, 2002).

Comprehensive treatments targeting multiple problems are likely to be more effective in improving the perspective of the youth than treatments targeting a single behavioral problem (Whitmore \& Riggs, 2006). Problematic substance use and criminal offending are influenced by similar risk factors (Moffitt et al., 2002; Mulder, Vermunt, Brand, Bullens, \& van Marle, 2012). The two types of problem behaviors respond to the same kinds of treatment (Baldwin, Christian, Berkeljon, \& Shadish, 2012; Hogue, Henderson, Ozechowski, \& Robbins, 2014).

In forensic settings, treatment often is embedded in broader intervention programs, which may also include nontherapeutic guidance and counseling, and rehabilitation services targeting school, work, leisure time activities, and housing. A meta-analysis reviewing 28 studies found no evidence that intervention programs, overall, decreased criminal offending in adolescents (Schwalbe, Gearing, MacKenzie, Brewer, \& Ibrahim, 2012). In contrast, another meta-analysis, based on 73 studies, indicated that intervention programs may be of modest use in preventing recidivism (Wilson \& Hoge, 2013). No doubt, this discrepancy in results is partly due to the large heterogeneity of the studies included in these and other meta-analyses. Some of the studies selected for the various analysis samples focused on a disorder a youth might have (such as conduct disorder), others on measures of self-reported or registered (e.g., police arrests) offenses, and yet others on a specific judicial program or process (such as cautioning, diversion, probation, detention, and postrelease rehabilitation). Added to this heterogeneity is the large variety of intervention approaches, ranging from minimal interventions to a score of individual treatments and to family therapy. Comparison of studies was further hampered by differences and weaknesses in the organization of the intervention programs considered (Wilson \& Hoge, 2013).

Nevertheless, a few conclusions can be drawn. Programs involving individual treatment of the adolescent may reduce recidivism, though generally the effect is small and transient (Henderson, Dakof, Greenbaum, \& Liddle, 2010; van der Pol et al., 2017; van der Stouwe, Asscher, Stams, Deković, \& van der Laan, 2014; von Sydow, Retzlaff, Beher, Haun, \& Schweitzer, 2013). On average, cognitive behavior therapy (CBT) has the best record among individual treatments (Greenberg \& Lippold, 2013; Smeets et al., 2015; von Sydow et al., 2013). Even better treatment results have been obtained with family therapy. In systematic literature reviews (Greenberg \& Lippold, 2013; von 
Sydow et al., 2013), meta-analyses (Baldwin et al., 2012; Schwalbe et al., 2012; van der Pol et al., 2017; van der Stouwe et al., 2014), and randomized controlled trials comparing family therapy with CBT (Henderson et al., 2010; Hendriks, van der Schee, \& Blanken, 2011; Schaub et al., 2014), family therapy generally outperformed CBT on one or more measures of recidivism or other antisocial behavior.

An example of a well-established family-based treatment approach is multidimensional family therapy (MDFT; Stanton, 2015). MDFT is an outpatient and inpatient treatment program for adolescents displaying problem behavior. The term multidimensional means that each major domain in the life of an adolescent is seen as contributing to the incidence and persistence of behavioral problems (through risk factors) and as potentially helpful in resolving such problems (through protective factors). The life domains include the youth him- or herself, parents, family, friends and peers, school and work, and leisure time. MDFT has been found to be more effective than active comparison therapies in various adolescent populations, doses and treatment delivery settings (Greenbaum et al., 2015; Liddle, 2010).

Most findings regarding MDFT are from U.S.-based randomized controlled trials initiated by the developers of this treatment program. (Junior-) Ministers of Health from five Western European countries decided to have MDFT independently tested in a European context, in a trial named INCANT (International Cannabis Need of Treatment study) comparing MDFT with individual psychotherapy (IP; Rigter et al., 2010). INCANT confirmed the pattern of results from American trials. The European therapists delivered MDFT with a high degree of fidelity (Rowe et al., 2013). The therapy improved treatment motivation and lowered cannabis disorder rates in adolescents from outpatient treatment sites in Berlin, Brussels, Geneva, Paris, and The Hague (Rigter et al., 2013), and decreased the number of symptoms of externalizing disorders (Schaub et al., 2014).

One of the INCANT sites (The Hague) examined the relationship between cannabis use and criminal offending. In delinquent as compared with nondelinquent youth, MDFT outperformed IP in decreasing the number of days on which cannabis was consumed (Hendriks, van der Schee, \& Blanken, 2013). In U.S.-based studies, MDFT lowered criminal offense rates in adolescents regardless of its effect on substance abuse in Drug Court and diversion settings (Dakof et al., 2015; Liddle, Rowe, Dakof, Henderson, \& Greenbaum, 2009). These findings led us to examine MDFT's effect on criminal offending in European adolescents in more detail. In designing INCANT, two of the five INCANT sites - Geneva and The Hague - decided to extend the basic battery of assessments with the Self-Report Delinquency (SRD) Scale. The SRD records the number and types of criminal offenses committed by the adolescents over the previous 90 days.

\section{Objectives}

The purpose of our study was to examine the effects of MDFT on self-reported criminal offending. We describe here the SRD outcomes for the Geneva and The Hague INCANT sites addressing two hypotheses: 
Hypothesis 1: Across the 12-month follow-up period, both MDFT and IP will decrease the proportion of youth engaged in criminal offenses, and will reduce the number of offenses committed.

Hypothesis 2: MDFT is more effective than IP on both types of outcome measure.

\section{Method}

\section{Approval}

INCANT was approved by medical ethical committees in all involved countries (Rigter et al., 2010). For Geneva, approval was granted by the Ethical Board for Clinical and Outpatient Research (Medical Association Geneva Canton; Switzerland), and for The Hague by the Medical Ethical Board for the Mental Health Sector in the Netherlands (METiGG).

\section{Sample and Treatment Sites}

Across the treatment sites in the five countries supporting INCANT, the total number of adolescents recruited for the study was 450 . The study flow diagram was published by Rigter et al. (2013). The site (two subsites) in The Hague contributed 109 adolescents and the site in Geneva 60, yielding a sample of 169 participants for the current study.

To be included in INCANT, youth (boys and girls) had to be between 13 and 18 years of age and meet criteria for a cannabis use disorder (abuse or dependence) based on the Diagnostic and Statistical Manual of Mental Disorders (4th ed.; DSM-IV; American Psychiatric Association, 1994), which was the manual in use when the study was carried out. Dependence and abuse were diagnosed, respectively, if at least three of seven dependence criteria or one of four abuse criteria had been met. In addition, at least one parent had to indicate that he or she would participate in the treatment if they were randomized to the MDFT condition. Adolescents were excluded if they were requiring inpatient treatment because of psychosis, advanced eating disorder, or severe suicidal ideation (Rigter et al., 2010).

The treatment centers recruited for INCANT were nominated by government officials working together in the INCANT Steering Committee. The sites were visited by MDFT trainers and European project staff and were asked to give presentations and to submit documentation on the mission and funding of the center, training level and professional background of the therapists, sources of referral of cases, caseload, treatments delivered, and links with research groups. All sites offered outpatient treatment to adolescents with substance use disorders.

The Geneva site was Phénix. In 2004, this foundation created a unit for treating adolescents with substance use disorders. Treatment staff included a psychiatrist, psychologists, and social workers. Phénix is a private, nonprofit organization, with treatment costs covered by basic health insurance. 
There were two treatment subsites in The Hague. First, Parnassia Brijder-now called Brijder Addiction Care - which among other services offers treatment programs for adolescents with substance abuse problems. The second subsite was Palmhuis, the forensic unit of De Jutters, which is the child and adolescent mental health institute serving The Hague and the surrounding region. Both sites are private, nonprofit organizations, with treatment being paid, at the time of the study, by national, regional, and local governments and through insurance funds. The MDFT team was a joint enterprise of the two subsites, with therapists (psychologists and social workers) from both organizations being members of the team.

\section{Treatments}

At both sites, the therapists were experienced in treating behaviorally troubled adolescents. In Geneva, MDFT was delivered by three MDFT certified therapists and IP by another three therapists. The corresponding numbers for The Hague were six and 12 therapists. The characteristics of these professionals (age, gender, years of experience, background) did not differ between Geneva and The Hague, or between the two treatment conditions (Rowe et al., 2013).

When preparing for INCANT, we assessed the usual treatment provided at each of the recruited sites. Although sites confessed to different theoretical orientations, for example, mainly psychodynamic in Geneva and cognitive-behavioral in The Hague, in practice treatment as usual was IP, consistently involving enhancement of treatment motivation, sessions with the individual adolescents (not with the parent(s) except to inform them on treatment progress), and relapse prevention (Rigter et al., 2013; Rigter et al., 2010).

MDFT consists of three stages. The first one focuses on intensively enhancing treatment motivation, building multiple therapeutic alliances, and drafting the treatment plan. In Stage 2, treatment plan interventions targeting the youth and his or her family are carried out, including education about adolescence, behavioral development, and risk factors for problem behavior; relapse prevention; improving family communication and relationships; and strengthening parental educational skills. Stage 3 involves sealing off the treatment, agreeing on a relapse prevention plan, and providing booster sessions if needed.

In INCANT, both MDFT and IP were scheduled to last for 6 months. MDFT was delivered in approximately two sessions per week - in roughly equal proportion to be held with the adolescent, parent(s), and family (adolescent and parent(s) together). In IP, the number of sessions with the adolescent was matched to be similar to MDFT. However, the total number of IP sessions was lower than for MDFT, as there were no sessions with parents and family. Rowe et al. (2013) present details on the actual treatment dose received; this article also documents the efforts to evaluate and safeguard treatment integrity and fidelity.

\section{Design}

INCANT was a multicenter Phase III(b) randomized controlled effectiveness trial with an open label, parallel group design, running from 2006 to 2010. Assessments were 
scheduled at baseline - immediately before randomization and start of treatment—and at 3, 6, 9, and 12 months thereafter (Rigter et al., 2010). The SRD was administered at baseline and 6- and 12-month follow-up.

Randomization occurred immediately after the eligibility of the case had been confirmed at baseline. The INCANT database, at the Department of Public Health of Erasmus Medical Centre in Rotterdam, assigned a code to each new case entered by a site's research assistant and automatically informed her about the allocated treatment. To conceal the randomization process, trial staff was not involved in any step of the procedure (Rigter et al., 2010).

\section{Outcome Measures}

The measurements were delivered at baseline, at 6 months (if planned), and at 12-month follow-up.

Cannabis use. Frequency of cannabis use by the adolescents was recorded with the Timeline Follow-Back (TLFB) method, as adapted and validated for adolescents (Waldron, Slesnick, Brody, Turner, \& Thomas, 2000). The TLFB obtains reports of daily cannabis use for the 90 days preceding the assessment, using a calendar and other memory prompts.

Cannabis use disorders (abuse and dependence). Cannabis use disorders were identified with the Adolescent Diagnostic Interview-Light (ADI-Light). This structured multiaxial interview generating $D S M-I V$ diagnoses has good psychometric properties, as assessed in reliability and validity tests (Winters \& Henly, 1993). The ADI-Light was administered at baseline and at 12-month follow-up.

Criminal offenses. To trace the number and type of offenses committed by the adolescents, we administered the SRD, the SRD Scale (Elliott, Huizinga, \& Ageton, 1985), asking the youth how many and which type of criminal offenses they had committed in the past 90 days. We analyzed SRD scores for the classes of property crimes and of violent crimes (aggression, violent sexual offense, and violent property offense), respectively, and for these types of crimes together (total scores). The SRD scored well in tests of reliability and validity (Elliott et al., 1985).

\section{Statistical Analyses}

Baseline characteristics. Between-treatment equivalence was tested with analyses of variance for continuous variables, and chi-square tests for categorical variables.

Changes over time across treatment conditions. Latent growth curve (LGC) modeling with robust maximum likelihood estimation was used to analyze change for each adolescent. The missing at random (MAR) assumption could not be directly evaluated. We explored the reasonableness of the MAR assumption holding with these data by 
checking whether there were significant correlations between key study variables and a binary variable indicating whether the data were missing or not $(1=$ missing at follow-up assessment, $0=$ not missing). As correlations were negligible $(r<0.10)$, we treated incomplete data as MAR and accounted for it in subsequent models using Full Information Maximum Likelihood estimation (Little \& Rubin, 2002). We included a dummy coded variable representing treatment condition (IP $=0 ;$ MDFT $=1)$ in the model to test the equivalence of groups at baseline and the impact of intervention type on change over time (i.e., the intercept and slope growth parameters). Intervention effects were demonstrated by a statistically significant slope parameter, as tested by the pseudo-z test associated with treatment condition. LGC modeling was carried out with Mplus (Version 7.1; Muthén \& Muthén, 2016).

Density plots revealed a high proportion of participants reporting no criminal offenses at each follow-up assessment. Therefore, we used a two-part growth modeling approach (Brown, Catalano, Fleming, Haggerty, \& Abbott, 2005; Liddle et al., 2009) to estimate separate but correlated continuous and categorical LGC models. This approach was developed to address nonnormality caused by a preponderance of zeros (Olsen \& Schafer, 2001). As implemented in Mplus, two-part growth modeling applies a natural log transformation to the continuous outcomes. The modeling approach was successful in bringing skewness and kurtosis below acceptable levels (below 1.5). Furthermore, we used the robust maximum likelihood estimator for all analyses to minimize the impact of nonnormality on the results.

Effect sizes. The effect size parameter $d$ for treatment comparisons was computed using Feingold's (2009) method for calculating effect sizes with growth curve models. A $d$ in the range of 0.30 to 0.70 indicates that the effect was of moderate size; higher $d$ values reflect strong effects.

\section{Results}

\section{Missing Values}

There were no missing data at baseline. At 12-month follow-up, $28 \%$ of the adolescents did not complete the SRD. There were no differences between treatments in this respect, $\chi^{2}(1)=0.40$. However, the rate of missing SRD forms was higher in Geneva than in The Hague, $\chi^{2}(1)=50.62, p<0.01$.

\section{Baseline}

Table 1 presents baseline data for the two sites and two treatment conditions. Both across sites (the columns "Total") and per site, the adolescents from the two treatment conditions were similar in age and gender, and in characteristics of their parents (divorce rate; prevalence of mental health and substance use problems). However, when comparing the two sites with each other across treatment conditions, the two populations of adolescents differed in foreign descent-rate higher in Geneva; $\chi^{2}(4)=10.88, p=$ 
Table I. Baseline Data for the The Hague and Geneva Sites.

\begin{tabular}{|c|c|c|c|c|c|c|}
\hline Variable & $\begin{array}{l}\text { The Hague, } \\
\text { MDFT }\end{array}$ & $\begin{array}{c}\text { The Hague, } \\
\text { IP }\end{array}$ & $\begin{array}{l}\text { Geneva, } \\
\text { MDFT }\end{array}$ & Geneva, IP & $\begin{array}{l}\text { Total, } \\
\text { MDFT }\end{array}$ & Total, IP \\
\hline$M_{\text {age }} \pm S D$ & $16.2 \pm 1.3$ & $16.3 \pm 1.2$ & $16.1 \pm 1.2$ & $16.0 \pm 1.2$ & $16.2 \pm 1.3$ & $16.2 \pm 1.2$ \\
\hline Male & $80 \%$ & $80 \%$ & $90 \%$ & $93 \%$ & $83 \%$ & $85 \%$ \\
\hline From foreign descent & $46 \%$ & $48 \%$ & $73 \%$ & $60 \%$ & $58 \%$ & $55 \%$ \\
\hline Attending school & $77 \%$ & $74 \%$ & $67 \%$ & $70 \%$ & $74 \%$ & $73 \%$ \\
\hline Living with family & $98 \%$ & $98 \%$ & $82 \%$ & $83 \%$ & $90 \%$ & $93 \%$ \\
\hline Parents separated & $60 \%$ & $56 \%$ & $63 \%$ & $53 \%$ & $61 \%$ & $55 \%$ \\
\hline $\begin{array}{l}\text { Parents with mental } \\
\text { health or substance use } \\
\text { problems }\end{array}$ & $29 \%$ & $26 \%$ & $33 \%$ & $33 \%$ & $31 \%$ & $29 \%$ \\
\hline \multicolumn{7}{|l|}{ Behavior } \\
\hline $\begin{array}{l}\text { Totala number of self- } \\
\text { reported criminal } \\
\text { offenses } \pm S D^{b}\end{array}$ & $5.8 \pm 13.8$ & $6.4 \pm 18.5$ & $8.5 \pm 18.6$ & $8.9 \pm 20.3$ & $6.8 \pm 15.6$ & $7.3 \pm 19.1$ \\
\hline Cannabis use days $\pm S D^{\mathrm{b}}$ & $64 \pm 23$ & $61 \pm 24$ & $47 \pm 25$ & $52 \pm 29$ & $58 \pm 25$ & $58 \pm 26$ \\
\hline Cannabis dependence & $73 \%$ & $78 \%$ & $90 \%$ & $97 \%$ & $77 \%$ & $77 \%$ \\
\hline
\end{tabular}

Note. MDFT = multidimensional family therapy; IP = individual psychotherapy.

aCriminal offenses $=$ property and violent crimes taken together.

bln the 90 days before the baseline assessment.

0.03 - and proportion of youth living with their family - rate higher in The Hague; $\chi^{2}(3)=13.48, p=0.004$. Also, the two populations were distinct from each other on cannabis use measures - days of use: $F(1,167)=9.56, p=0.002$; proportion of adolescents being dependent on cannabis: $\chi^{2}(1)=17.13, p<0.001$. Cannabis dependence was more common among the adolescents in Geneva than in The Hague, although the selfreported number of cannabis use days was lower in Geneva. Within sites, the variables mentioned did not statistically differ between the two treatment conditions.

\section{Change in Criminal Offense Rate}

Preliminary analyses. At baseline, $43 \%$ of the adolescents said that they had not committed any criminal offense in the preceding 90 days. Forty-eight percent of participants reported they had committed a property crime, and $33 \%$ a violent crime. At this point in time, there were no differences between treatment groups in proportion of adolescents reporting any- $\chi^{2}(1)=3.06, n s-$ property- $\chi^{2}(1)=1.21, n s-$ or violent $-\chi^{2}(1)=2.83, n s$ - crimes.

Offenses of any type: Changes over time across treatment conditions. Over the 12-month follow-up period and across sites, the number of self-reported criminal offenses dropped in both the MDFT and IP groups, with $70 \%$ and $46 \%$, respectively, with no significant difference noted. Looking per site, the decline in number of offenses was similar in the MDFT and IP groups in The Hague (77\% vs. $72 \%)$, but dissimilar in Geneva (35\% decrease in the MDFT condition vs. 35\% increase for IP). 


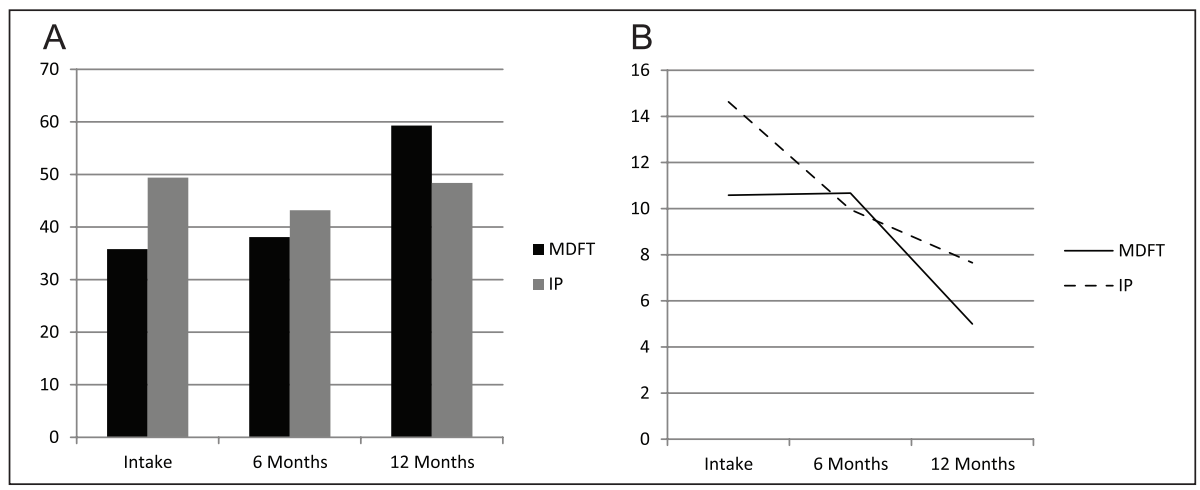

Figure I. Change in proportion of youth reporting abstaining from delinquency $(A)$ and number of delinquent acts among those persisting in delinquent behavior (B). Note. MDFT = multidimensional family therapy; IP = individual psychotherapy.

Across treatments, the proportion of youth reporting no criminal offenses (represented by the categorical part of the frequency model) slightly increased from baseline to follow-up assessments (mean slope $=-0.28, S E=0.16$, pseudo- $z=-1.79, p=0.07$ ). Among those reporting they had engaged in criminal offending during the study period (the continuous part of the model), the number of criminal offenses decreased over time (mean slope $=-0.21, S E=0.08$, pseudo- $z=-2.54, p=0.01$ ).

Abstaining from criminal offending:Treatment comparisons. Comparing the treatments in the categorical model, more youth receiving MDFT reported abstaining from any type of criminal offense over time than corresponding IP youth (treatment slope = $-0.70, S E=0.33$, pseudo- $z=-2.14, p=0.03, d=0.51)$ (Figure 1A). This pattern of results held for both property crimes (slope $=0.34, S E=0.05$, pseudo- $z=6.92, p<$ $0.01, d=4.95$ ) and violent crimes (slope $=0.39, S E=0.05$, pseudo- $z=8.53, p<$ $0.01, d=7.53)$.

As for the number of criminal offenses of any type, the two treatments did not differ in the continuous part of the model (treatment slope $=-0.01, S E=0.17$, pseudo- $z=$ $-0.07, n s, d=0.01$; see Figure 1B). The number of total criminal offenses declined in both treatment groups, with no advantage of MDFT over IP. The decrease in the number of criminal offenses was marginally larger in The Hague than in Geneva (slope = $0.29, S E=0.17$, pseudo- $z=1.68, p=0.09, d=0.79)$.

Committing property crimes versus violent crimes:Treatment comparisons. We divided the total criminal offenses category into property and violent crimes. Among youth engaging in property crimes over the 12-month follow-up period, the number of these offenses among those reporting delinquent behavior dropped over time (slope $=-0.37$, $S E=0.17$, pseudo- $z=-2.17, p=0.03$ ); Figure 2. MDFT and IP did not differ in this respect in either the continuous (slope $=-0.11, S E=0.22$, pseudo- $z=-0.50, n s$, 


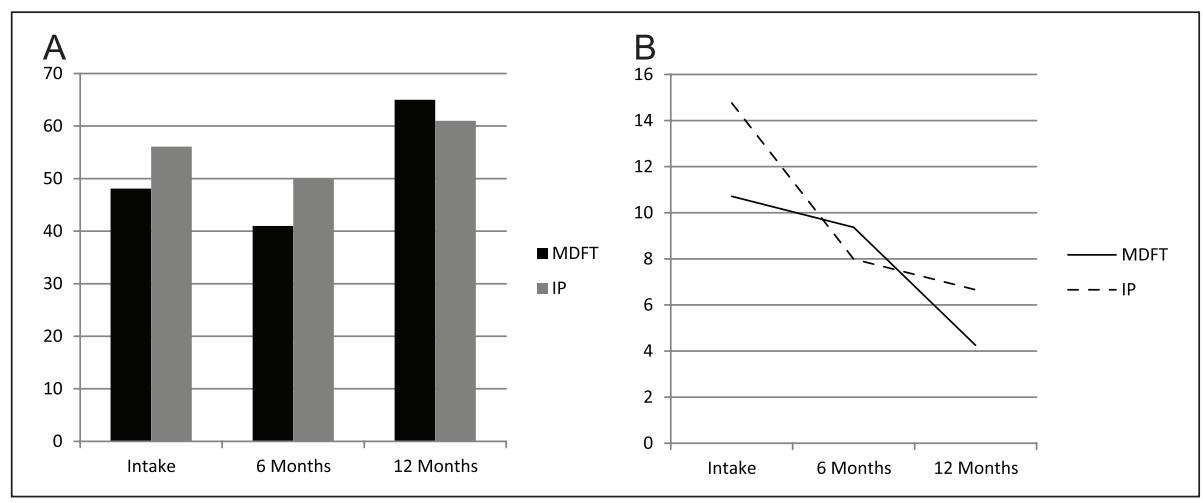

Figure 2. Change in proportion of youth reporting abstaining from property crimes $(A)$ and number of property crimes among those committing property crimes (B).

Note. MDFT = multidimensional family therapy; IP = individual psychotherapy.

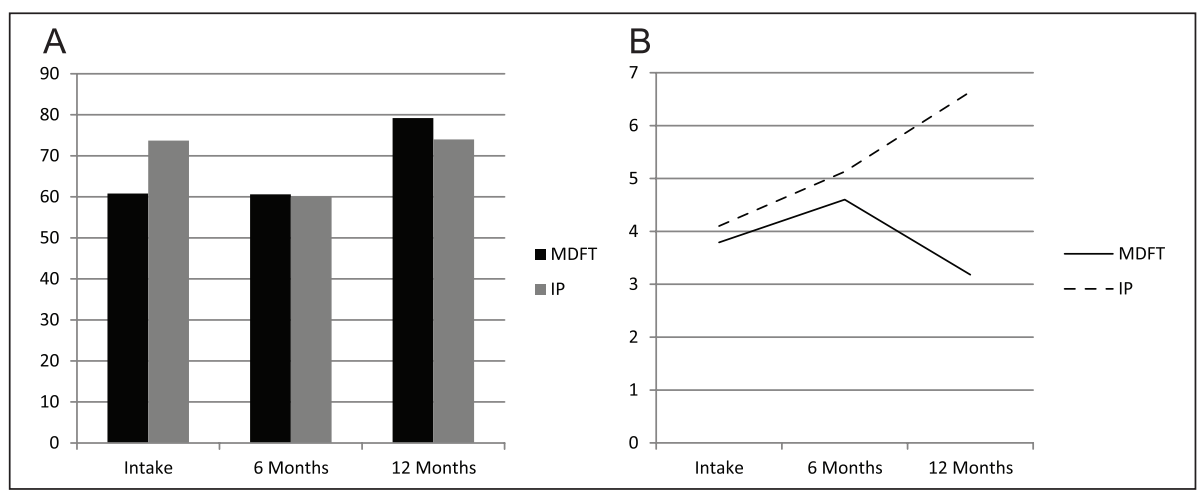

Figure 3. Change in proportion of youth reporting abstaining from violent crimes $(A)$ and number of violent crimes among those committing violent crimes (B).

Note. $\mathrm{MDFT}=$ multidimensional family therapy; IP = individual psychotherapy.

$d=0.10$ ) or categorical part of the model (slope $=0.07, S E=0.06$, pseudo- $z=1.18$, $n s, d=0.28)$.

For violent crimes, the overall proportion of adolescents engaging in violent crimes did not change over time (slope $=0.02, S E=0.03$, pseudo- $z=0.46, n s$ ). However, when treatment condition was entered into the calculations, more youth receiving MDFT rather than IP reported to have abstained from violent offenses (slope $=0.10$, $S E=0.05$, pseudo- $z=2.07, p=0.04, d=0.43$; Figure 3A).

The number of violent crimes among self-reported violent offenders did not change over time (slope $=0.11, S E=0.15$, pseudo- $z=0.74, n s$ ). Comparing the two treatments, the adolescents receiving MDFT tended to commit fewer violent offenses over time than their IP counterparts, but although the effect size was moderately large, the difference between the treatment groups was not statistically significant (slope $=0.23$, $S E=0.20$, pseudo- $z=1.13, n s, d=0.63$; Figure $3 \mathrm{~B}$ ). 


\section{Discussion}

All adolescents in the present study had a cannabis use disorder at baseline, mostly cannabis dependence. Half of them reported having committed one or more criminal offenses in the 90 days before the baseline assessment, that is, the moment of their recruitment in the INCANT randomized trial. Across all youth, the number of selfreported criminal offenses per period of 6 months dropped going from baseline to the 12-month follow-up assessment. In other words, both MDFT and IP appeared to be effective in decreasing criminal behavior, in accordance with our first study hypothesis. MDFT was as effective in this respect as IP, which would appear to run counter to our second study hypothesis, which stated that MDFT would outperform IP.

Yet, the second study hypothesis was confirmed in part. Dividing criminal offenses into property and violent crimes revealed a treatment difference. The drop in property crimes was similar in the MDFT and IP conditions, but the decrease in violent crimes was larger for MDFT than for IP.

We do not know of any publications clearly showing differential treatment effects on committing property crimes versus violent crimes in adolescents. The offense measures used by Dakof et al. (2015), who found MDFT to be superior to Drug Court group therapy, included "serious crimes," but without clear distinction between property and violent offenses. However, there are epidemiological data suggesting that treatment of delinquent adolescents should be tuned to certain characteristics of these youth. The literature contains many attempts to draft a typology of delinquent youth. Most often mentioned (disregarding sexual offenders) is the distinction between violent offenders, nonviolent (property) offenders, and versatile offenders who commit both violent and property crimes (Lai, Zeng, \& Chu, 2016). For these three classes of adolescent offenders, different profiles of risk factors apply (Colins, Vermeiren, Schuyten, \& Broekaert, 2009; Lai et al., 2016; Mulder et al., 2012). Most impaired in risk factor exposure and mental and behavioral health are the versatile offenders (Lai et al., 2016), who in our study were labeled as violent offenders, because violent property crimes were classified as violent offenses. The excess of risk factors facing violent/versatile offenders appears to be concentrated on the "mental comorbidity" (Colins et al., 2009), "family" (e.g., poor parental supervision), and "peers" (wrong friends) dimensions (Lai et al., 2016; Mulder et al., 2012).

Why would family therapy work out better in reducing delinquency in adolescents than individual therapy? Both types of treatment are effective in decreasing criminal offending. The surplus value of family therapy may be explained by the ambition to have this type of treatment address risk factors not only at the individual level (the adolescent with his or her personality traits and response patterns) but also at the family, peers, school/work, and leisure time levels. The latter factors strongly influence the behavior of an adolescent (Lai et al., 2016; Leve, Chamberlain, \& Kim, 2015; Wilson \& Hoge, 2013), strengthening the case for family therapy.

MDFT is not the only family therapy with credits in treating criminal youth. From U.S. research, five major programs have emerged (Leve et al., 2015), with multisystemic therapy (MST) and MDFT probably having the best research record in Europe, in addition to good performance in the United States (van der Pol et al., 2017; van der Stouwe et al., 2014). 
The evidence suggests that MDFT has effect in "light" cases, but certainly is to be preferred in "severe" cases. In substance abuse research (Henderson et al., 2010; Rigter et al., 2013), MDFT was as effective as IP in reducing problem behavior for all cases together. However, MDFT did better than IP in "severe" cases, however defined. Our present results suggest that the same may be true for the effect of treatment on criminal offending in adolescents. MDFT and IP are both effective in reducing selfreported criminal offenses, but MDFT outperforms IP in violent/versatile offenders, who might have been more severely impaired than the offenders committing property crimes (Colins et al., 2009). Clearly, more research is needed here.

A special finding of our study was that MDFT may not only lower recidivism rates, but also may help to prevent first-time offenses. In our trial, the proportion of nondelinquent youth grew somewhat during the study period, most clearly so for adolescents receiving MDFT. A recent meta-analysis confirmed that intervention programs may prevent (the first incident of) criminal offending. Effective programs are family-oriented and "multimodal" (multidimensional, in MDFT's terminology; de Vries, Hoeve, Assink, Stams, \& Asscher, 2015). Our findings are in keeping with this conclusion.

A strength of the INCANT trial was that it excluded few adolescents from taking part in the study. The trial's aim was to achieve a high external validity level. The sites differed in many respects, such as in referral practices, that is, the route of bringing an adolescent and his or her family into contact with a treatment center. Many Swiss adolescents recruited for INCANT had been referred to the trial by a juvenile judge. So, the high rate of criminal offending in the Geneva youth is not surprising. The adolescents from The Hague, who more often were referred from non-Justice sources, were probably less impaired than the Geneva youth (Phan et al., 2011). Yet, despite these differences in referral pathways, MDFT appeared to be effective at all sites in all countries (Phan et al., 2011; Rigter et al., 2013). This is confirmed in the present article.

A possible weakness of the study was that the criminal offense data were based on self-report. Self-report data may be biased. However, the jury is still out on the question if supposedly more objective database records (on arrests, convictions) are a better source of information (Kirk, 2006). Database records only contain data on registered criminal offenses; self-report invites respondents to also report criminal offenses that went unnoticed to police and justice authorities. In a separate paper, we will describe results for a database measure of criminal offending, that is, police arrests of The Hague INCANT youth in the 3 years following randomization, which confirmed that MDFT lowers criminal offense rates in adolescents.

From a policy perspective, we would recommend that in juvenile forensic settings, treatment programs are to be implemented that do not focus on just one behavioral problem, but on the common multiplicity of behavioral problems. Also, it is advisable to opt for an evidence-based family therapy rather than an individual treatment targeting the adolescent him- or herself. The broader approach of family therapy is likely to more strongly reduce recidivism rates of serious (violent/versatile) crimes than individual treatment, in addition to having a preventive effect on criminal offending in general. 


\section{Author Contributions}

H.R., C.H., and V.H. were key members of the team designing the INCANT trial. H.R. and V.H. helped in getting the trial funded (Trial Registration ISRCTN51014277). H.R. was overall project leader of INCANT (International Cannabis Need of Treatment study), and V.H. and M.S. were project leader of the Dutch and Swiss parts of INCANT, respectively. These project leaders were responsible for data collection. C.H. developed the statistical models and carried out the analyses, also in the present study. T.P. initiated and designed the present study. H.R., C.H., and T.P. drafted the manuscript. All authors read and approved the final manuscript.

\section{Declaration of Conflicting Interests}

The author(s) declared no potential conflicts of interest with respect to the research, authorship, and/or publication of this article.

\section{Funding}

The author(s) disclosed receipt of the following financial support for the research, authorship, and/or publication of this article: This research has been funded by the federal Ministries of Health of the Netherlands and Switzerland. These agencies did not influence any part of the study (design, data collection, data interpretation, and reporting).

\section{References}

American Psychiatric Association. (1994). Diagnostic and statistical manual of mental disorders (4th ed.). Washington, DC: Author.

Baldwin, S. A., Christian, S., Berkeljon, A., \& Shadish, W. R. (2012). The effects of family therapies for adolescent delinquency and substance abuse: A meta-analysis. Journal of Marital and Family Therapy, 38, 281-304.

Brown, E. C., Catalano, R. F., Fleming, C. B., Haggerty, K. P., \& Abbott, R. D. (2005). Adolescent substance use outcomes in the raising healthy children project: A two-part latent growth curve analysis. Journal of Consulting and Clinical Psychology, 73, 699-710.

Colins, O., Vermeiren, R., Schuyten, G., \& Broekaert, E. (2009). Psychiatric disorders in property, violent, and versatile offending detained male adolescents. American Journal of Orthopsychiatry, 79, 31-38.

Copeland, J., \& Swift, W. (2009). Cannabis use disorder: Epidemiology and management. International Review of Psychiatry, 21, 96-103.

Dakof, G. A., Henderson, C. E., Rowe, C. L., Boustani, M., Greenbaum, P. E., Wang, W., . . . Liddle, H. A. (2015). A randomized controlled trial of family therapy in Juvenile Drug Court. Journal of Family Psychology, 29, 232-241.

de Vries, S. L. A., Hoeve, M., Assink, M., Stams, G. J. J. M., \& Asscher, J. J. (2015). Practitioner review: Effective ingredients of prevention programs for youth at risk of persistent juvenile delinquency-Recommendations for clinical practice. Journal of Child Psychology and Psychiatry, 56, 108-121.

Elliott, D. S., Huizinga, D., \& Ageton, S. S. (1985). Explaining delinquency and drug use. Beverly Hills, CA: SAGE.

Fallu, J. S., Brière, F. N., \& Janosz, M. (2014). Latent classes of substance use in adolescent cannabis users: Predictors and subsequent substance-related harm. Frontiers in Psychiatry, 5, Article 9. 
Feingold, A. (2009). Effect sizes for growth-modeling analysis for controlled clinical trials in the same metrics as for classical analysis. Psychological Methods, 14, 43-53.

Greenbaum, P. E., Wang, W., Henderson, C. E., Kan, L., Dakof, G. A., \& Liddle, H. A. (2015). Gender and ethnicity as moderators: Integrative data analysis from Multidimensional Family Therapy randomized clinical trials. Journal of Family Therapy, 29, 919-930.

Greenberg, M. T., \& Lippold, M. A. (2013). Promoting healthy outcomes among youth with multiple risks: Innovative approaches. Annual Review of Public Health, 34, 253-270.

Griffith-Lendering, M. F. H., Huijbregts, S. C. J., Mooijaart, A., Vollebergh, W. A. M., \& Swaab, H. (2011). Cannabis use and development of externalizing and internalizing behaviour problems in early adolescence: A TRAILS study. Drug and Alcohol Dependence, 116, 11-17.

Henderson, C. E., Dakof, G. A., Greenbaum, P. E., \& Liddle, H. A. (2010). Effectiveness of multidimensional family therapy with higher severity substance-abusing adolescents: Report from two randomized controlled trials. Journal of Consulting and Clinical Psychology, 78, 885-897.

Hendriks, V. M., van der Schee, E., \& Blanken, P. (2011). Treatment of adolescents with a cannabis use disorder: Main findings of a randomised controlled trial comparing multidimensional family therapy and cognitive behavioral therapy in the Netherlands. Drug and Alcohol Dependence, 119, 64-71.

Hendriks, V. M., van der Schee, E., \& Blanken, P. (2013). Multidimensionele gezinstherapie en cognitieve gedragstherapie bij adolescenten met een stoornis in het gebruik van cannabis; een gerandomiseerd onderzoek [Multidimensional family therapy and cognitive behavioural therapy in adolescents with a cannabis use disorder: A randomised controlled trial]. Tijdschrift voor Psychiatrie, 55, 747-759.

Hogue, A., Henderson, C. E., Ozechowski, T. J., \& Robbins, M. S. (2014). Evidence base on outpatient behavioral treatments for adolescent substance use: Updates and recommendations 2007-2013. Journal of Clinical Child \& Adolescent Psychology, 43, 695-720.

Hser, Y. I., Grella, C. E., Hubbard, R. L., Hsieh, S. C., Fletcher, B. W., Brown, B. S., \& Anglin, M. D. (2001). An evaluation of drug treatments for adolescents in 4 US cities. Archives of General Psychiatry, 58, 689-695.

Hüsler, G., Plancherel, B., \& Werlen, E. (2005). Psychosocial predictors of cannabis use in adolescents at risk. Prevention Science, 6, 237-244.

Kirk, D. S. (2006). Examining the divergence across self-report and official data sources on inferences about the adolescent life-course of crime. Journal of Quantitative Criminology, 22, 107-129.

Lai, V., Zeng, G., \& Chu, C. M. (2016). Violent and nonviolent youth offenders. Youth Violence and Juvenile Justice, 14, 313-329.

Leve, L. D., Chamberlain, P., \& Kim, H. K. (2015). Risks, outcomes, and evidence-based interventions for girls in the U.S. Juvenile Justice System. Clinical Child and Family Psychology Review, 18, 252-270.

Liddle, H. A. (2010). Treating adolescent substance abuse using Multidimensional Family Therapy. In J. Weisz \& A. Kazdin (Eds.), Evidence-based psychotherapies for children and adolescents (pp. 416-432). New York, NY: Guildford Press.

Liddle, H. A., Rowe, C. L., Dakof, G. A., Henderson, C. E., \& Greenbaum, P. E. (2009). Multidimensional family therapy for young adolescent substance abuse: Twelve-month outcomes of a randomized controlled trial. Journal of Consulting and Clinical Psychology, 77, 12-25. 
Little, R. J. A., \& Rubin, D. B. (2002). Statistical analysis with missing data (2nd ed.). New York, NY: Wiley.

Moffitt, T. E., Caspi, A., Harrington, H., \& Milne, B. J. (2002). Males on the life-course persistent and adolescence-limited antisocial pathways: Follow-up at age 26 years. Developmental Psychopathology, 14, 179-207.

Mulder, E., Vermunt, J., Brand, E., Bullens, R., \& van Marle, H. (2012). Recidivism in subgroups of serious juvenile offenders: Different profiles, different risks? Criminal Behaviour and Mental Health, 22, 122-135.

Muthén, L. K., \& Muthén, B. O. (2016). Mplus user's guide (7th ed.). Los Angeles, CA: Author.

Olsen, M. K., \& Schafer, J. L. (2001). A two-part random-effects model for semicontinuous longitudinal data. Journal of the American Statistical Association, 96, 730-745.

Phan, O., Henderson, C. E., Angelidis, T., Weil, P., van Toorn, M., Rigter, R., . . . Rigter, H. (2011). European youth care sites serve different populations of adolescents with cannabis use disorder. Baseline and referral data from the INCANT trial. BMC Psychiatry, 11, Article 110.

Rigter, H., Henderson, C. E., Pelc, I., Tossmann, P., Phan, O., Hendriks, V., . . . Rowe, C. L. (2013). Multidimensional family therapy lowers the rate of cannabis dependence in adolescents: A randomised controlled trial in Western European outpatient settings. Drug and Alcohol Dependence, 130, 85-93.

Rigter, H., Pelc, I., Tossmann, P., Phan, O., Grichting, E., Hendriks, V., \& Rowe, C. (2010). INCANT: A transnational randomized trial of Multidimensional Family Therapy versus treatment as usual for adolescents with cannabis use disorder. BMC Psychiatry, 10, Article 28.

Rowe, C. L., Rigter, H., Gantner, A., Mos, K., Nielsen, P., Phan, O., \& Henderson, C. E. (2013). Implementation fidelity of Multidimensional Family Therapy in an international trial. Journal of Substance Abuse Treatment, 44, 391-399.

Schaub, M. P., Henderson, C. E., Pelc, I., Tossmann, P., Phan, O., Hendriks, V., . . . Rigter, H. (2014). Multidimensional family therapy decreases the rate of externalising behavioural disorder symptoms in cannabis abusing adolescents: Outcomes of the INCANT trial. BMC Psychiatry, 14, Article 26.

Schwalbe, C. S., Gearing, R. E., MacKenzie, M. J., Brewer, K. B., \& Ibrahim, R. (2012). A meta-analysis of experimental studies of diversion programs for juvenile offenders. Clinical Psychology Review, 32, 26-33.

Skeer, M., McCormick, M. C., Normand, S. T., Buka, S. L., \& Gilman, S. E. (2009). A prospective study of familial conflict, psychological stress, and the development of substance use disorders in adolescence. Drug and Alcohol Dependence, 104, 65-72.

Smeets, K. C., Leeijen, A. A. M., van der Molen, M. J., Scheepers, F. E., Buitelaar, J. K., \& Rommelse, N. N. J. (2015). Treatment moderators of cognitive behavior therapy to reduce aggressive behavior: A meta-analysis. European Child \& Adolescent Psychiatry, 24, 255-264.

Stanton, M. D. (2015). Family therapy. In M. Galanter, H. D. Kleber, \& K. Brady (Eds.), The American Psychiatric Publishing textbook of substance abuse treatment (5th ed., pp. 479495). Washington, DC: American Psychiatric Publishing.

van der Pol, T. M., Hoeve, M., Noom, M. J., Stams, G. J. J. M., Doreleijers, T. A. H., van Domburgh, L., \& Vermeiren, R. R. J. M. (2017). The effectiveness of multidimensional family therapy (MDFT) in treating substance abusing adolescents with comorbid behaviour problems: A meta-analysis. Journal of Child Psychology and Psychiatry (in press). 
van der Stouwe, T., Asscher, J. J., Stams, G. J. J. M., Deković, M., \& van der Laan, P. H. (2014). The effectiveness of multisystemic therapy (MST): A meta-analysis. Clinical Psychology Review, 34, 468-481.

von Sydow, K., Retzlaff, R., Beher, S., Haun, H. W., \& Schweitzer, J. (2013). The efficacy of systemic therapy for childhood and adolescent externalizing disorders: A systematic review of 47 RCT. Family Process, 52, 576-618.

Waldron, H. B., Slesnick, N., Brody, J. L., Turner, C. W., \& Thomas, R. (2000). Treatment outcomes for adolescent substance abuse at 4- and 7-month assessments. Journal of Consulting and Clinical Psychology, 69, 802-813.

Whitmore, E. A., \& Riggs, P. D. (2006). Developmentally informed diagnostic and treatment considerations in comorbid conditions. In H. A. Liddle \& C. L. Rowe (Eds.), Adolescent substance abuse: Research and clinical advances (pp. 264-283). Cambridge, UK: Cambridge University Press.

Wilson, H. A., \& Hoge, R. D. (2013). The effect of youth diversion programs on recidivism. A meta-analytic review. Criminal Justice and Behavior, 40, 497-518.

Winters, K. C., \& Henly, G. A. (1993). Adolescent diagnostic interview schedule and manual. Los Angeles, CA: Western Psychological Services. 